\title{
Development of a novel oil-in-water emulsion and evaluation of its potential adjuvant function in a swine influenza vaccine in mice
}

Jinqiu Zhang ${ }^{1} \mathbb{B}$, Jinfeng Miao ${ }^{2}$, Xiangan $\mathrm{Han}^{3}$, Yu Lu ${ }^{1 *}$, Bihua Deng ${ }^{1}$, Fang Lv ${ }^{1}$, Yanhong Zhao ${ }^{1}$, Chan Ding ${ }^{3}$ and Jibo $\mathrm{Hou}^{1}$

\begin{abstract}
Background: Vaccination is the principal strategy for prevention and control of diseases, and adjuvant use is an effective strategy to enhance vaccine efficacy. Traditional mineral oil-based adjuvants have been reported with post-immunization reactions. Developing new adjuvant formulations with improved potency and safety will be of great value.

Results: In the study reported herein, a novel oil-in-water (O/W) Emulsion Adjuvant containing Squalane (termed EAS) was developed, characterized and investigated for swine influenza virus immunization. The data show that EAS is a homogeneous nanoemulsion with small particle size $(\sim 105 \mathrm{~nm})$, low viscosity $\left(2.04 \pm 0.24 \mathrm{CP}\right.$ at $\left.20^{\circ} \mathrm{C}\right)$, excellent stability (at least 24 months at $4^{\circ} \mathrm{C}$ ) and low toxicity. EAS-adjuvanted H3N2 swine influenza vaccine was administrated in mice subcutaneously to assess the adjuvant potency of EAS. The results demonstrated that in mice EAS-adjuvanted vaccine induced significantly higher titers of hemagglutination inhibition (HI) and lgG antibodies than water-in-oil (W/ O) vaccines or antigen alone, respectively, at day 42 post vaccination (dpv) $(P<0.05)$. EAS-adjuvanted vaccine elicited significantly stronger IgG1 and IgG2a antibodies and higher concentrations of Th1 (IFN- $\gamma$ and IL-2) cytokines compared to the W/O vaccine or antigen alone. Mice immunized with EAS-adjuvanted influenza vaccine conferred potent protection after homologous challenge.

Conclusion: The O/W emulsion EAS developed in the present work induced potent humoral and cellular immune responses against inactivated swine influenza virus, conferred effective protection after homologous virus challenge and showed low toxicity in mice, indicating that EAS is as good as the commercial adjuvant MF59. The superiority of EAS to the conventional W/O formulation in adjuvant activity, safety and stability will make it a potential veterinary adjuvant.
\end{abstract}

Keywords: Swine influenza virus, Oil-in-water emulsion, H3N2 vaccine, Adjuvant

\footnotetext{
* Correspondence: luyu@jaas.ac.cn

${ }^{1}$ National Research Center for Veterinary Vaccine Engineering and

Technology of China, Jiangsu Academy of Agricultural Sciences, Nanjing

210014, China

Full list of author information is available at the end of the article
}

(c) The Author(s). 2018 Open Access This article is distributed under the terms of the Creative Commons Attribution 4.0 International License (http://creativecommons.org/licenses/by/4.0/), which permits unrestricted use, distribution, and reproduction in any medium, provided you give appropriate credit to the original author(s) and the source, provide a link to the Creative Commons license, and indicate if changes were made. The Creative Commons Public Domain Dedication waiver (http://creativecommons.org/publicdomain/zero/1.0/) applies to the data made available in this article, unless otherwise stated. 


\section{Background}

Vaccination is the principal strategy for prevention and control of diseases, and adjuvant use is an effective strategy to enhance vaccine efficacy. Emulsions have a long history as adjuvants for both human and animal vaccines. However, traditional oil-based emulsion adjuvants, such as Freund's complete or incomplete adjuvant, have been reported with post-immunization reactions. Developing new adjuvant formulations with improved potency and safety will be of great value.

Swine influenza is an acute respiratory disease of pigs mainly caused by the influenza A virus. Although mortality is usually low, swine influenza may result in poor growth, weight loss, immunosuppression of infected pigs and economic loss in the pig industry [1]. Furthermore, it has been hypothesized that pigs can serve as an intermediate host for the adaptation of avian influenza viruses to humans or as mixing vessels for the generation of reassortant viruses [2-4]. Vaccination is the primary strategy for prevention and control of swine influenza in China and other countries. However, previous studies demonstrate that commercial vaccines in a water-in-oil (W/ O) formulation is not highly effective in preventing vaccinated pigs from wild-type virus infection $[5,6]$. In addition, post-immunization reactions associated with mineral oil-based adjuvants have been reported, such as edema, abscess/granuloma formation or necrosis at injection sites, which render pork unfit for consumption and greatly limits the wide application of these vaccines [7]. Hence, developing new adjuvant formulations with improved potency and safety will be of great value and impact both in the swine industry and for global public health. In this study, swine influenza virus was used as a model antigen to investigate the new adjuvant's immunogenicity.

The most successful adjuvants of influenza vaccines for human use are squalene-based oil-in-water emulsions, such as MF59 (Novartis) and ASO3 (GlaxoSmithKline). A number of clinical trials indicate that squalene-in-water emulsions outperform aluminum salts or $\mathrm{W} / \mathrm{O}$ emulsions at increasing vaccine immunogenicity and affording cross-reactivity without causing unacceptable adverse reactions [8-11]. Squalene or squalane (hydrogenated form of squalene) has been used as an alternative to mineral oil for its tolerance and investigated extensively in vaccine adjuvant applications. In the current study, a new squalane-in-water $(\mathrm{O} / \mathrm{W})$ emulsion, termed EAS, was developed for veterinary vaccines. We describe the main physicochemical characteristics, stability and tolerability of the new O/W emulsion adjuvant. Then, vaccine supplemented with EAS was used to immunize mice subcutaneously to assess its capacity to induce a specific immune response. Our results show that EAS-adjuvanted H3N2 swine influenza vaccine can induce significantly higher antibody titers than W/O vaccines in mice, and elicit a mixed Th1/Th2 response. Compared to the conventional W/O formulation adjuvant, EAS was shown to be a better candidate for swine influenza immunization due to its superiority in adjuvant efficacy, stability and safety.

\section{Results}

\section{Characterization of the O/W emulsion EAS}

A novel emulsion formulation containing squalane, PEGPPG-PEG, soy lecithin and carbopol was prepared. Particle size, polydispersity index, zeta potential, viscosity, conductivity and $\mathrm{pH}$ value of the developed emulsion EAS were measured (Table 1). The mean particle size of the EAS emulsion was $105 \mathrm{~nm}$, with a low polydispersity index (Table 1 and Fig. 1a). TEM analysis was performed to investigate the morphology of emulsion droplets (Fig. 1b). Images from the O/W emulsion showed a characteristic spherical shape, and the diameter of emulsion droplets was in agreement with DLS measurements as described above. The zeta potential value of these emulsions was about $-38 \mathrm{mV}$, higher than the common slightly negative charge usually reported for other O/W emulsions [12]. EAS had a viscosity of $2.04 \pm 0.24 \mathrm{cP}$ at $20^{\circ} \mathrm{C}$. Conductivity measurements demonstrated that EAS is an oil-in-water system [13].

\section{Stability of the O/W emulsion EAS}

The stability of EAS at different storage temperatures was monitored by visual inspection and particle sizing change. At $4{ }^{\circ} \mathrm{C}$, the emulsion had minimal changes in particle size, zeta potential, $\mathrm{pH}$ value and viscosity over 24 months (Table 2). At elevated temperatures $\left(25\right.$ or $\left.37^{\circ} \mathrm{C}\right)$ the samples demonstrated stability over 6-month or 3-month durations, respectively. The samples stored at 25 or $37^{\circ} \mathrm{C}$ had an increase in particle size after 6 months or 3 months, respectively. Thereafter, visible evidence of coalescence or phase separation of the oil and aqueous phases gradually emerged. Overall, results provided in Table 2 support the long-term stability of EAS at $4{ }^{\circ} \mathrm{C}$.

\section{Toxicity evaluation of EAS}

To assess EAS tolerability in animals, the local reactogenicity of different formulations was monitored at injection sites for edema or erythema and animals were observed for health problems following injection. There were not any changes at the sites of injection in the PBS group (Fig. 2a). No systemic effects or gross lesions were noted post-administration of the EAS and MF59 formulations (Fig. 2 b and c). When

Table 1 Characteristics of the O/W emulsion adjuvant (values are shown as means $\pm S D, n=3$ )

\begin{tabular}{lcccccc}
\hline Visual appearance & Particle size (Dv50; $\mathrm{nm})$ & Polydispersity index (PDI) & Zeta potential (mV) & Viscosity (cP) & Conductivity (mS/cm) & $\mathrm{pH}$ \\
\hline Milky-white liquid & $105 \pm 2$ & $0.12 \pm 0.03$ & $-38.8 \pm 0.2$ & $2.04 \pm 0.24$ & $-0.0269 \pm 0.0017$ & $6.80 \pm 0.02$ \\
\hline
\end{tabular}




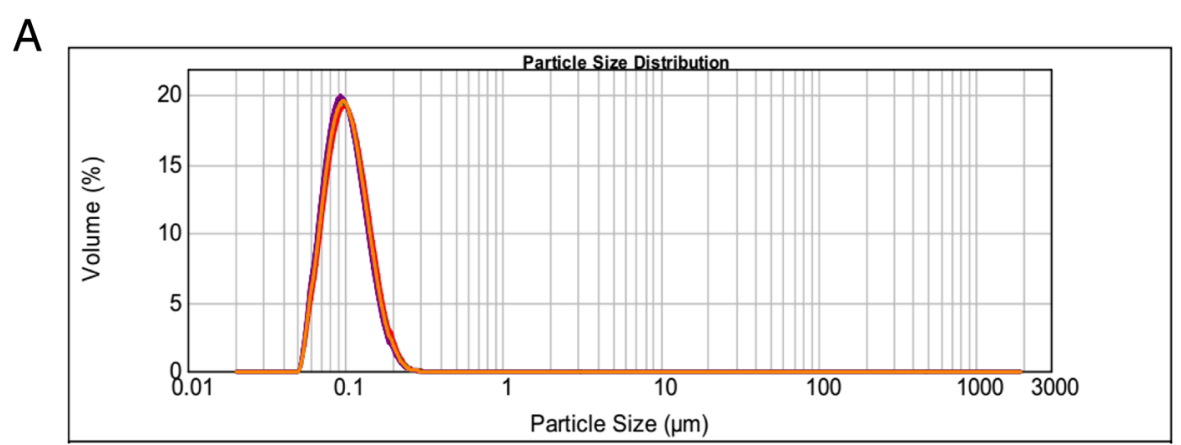

B
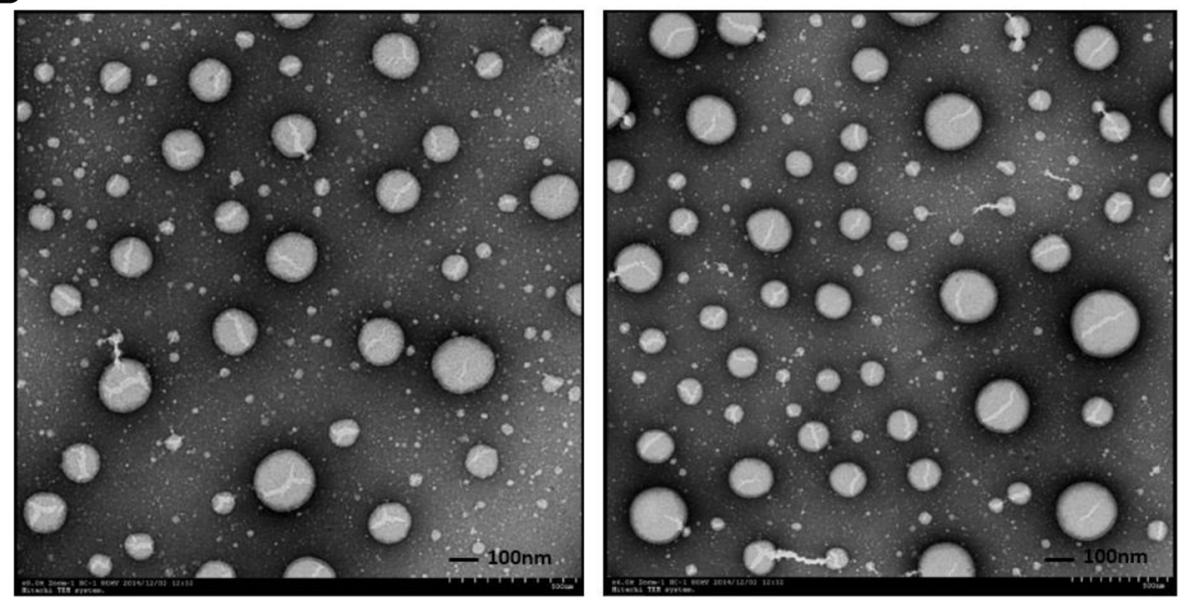

Fig. 1 The particle size distribution and TEM images of EAS. a: Nine total measurements were made on 3 separate samples from the same batch of EAS as measured by dynamic light scattering. $\mathbf{b}$ : Cryo-transmission electron microscopy of two samples of EAS. Bar represents $100 \mathrm{~nm}$

administered with the $\mathrm{W} / \mathrm{O}$ formulation, mild to serious reactions, such as edema, abscesses, granulomas and nodules were present at injection sites (Fig. 2d).

Histological analysis was used to evaluate the toxicity of the different formulations. No pathologic changes were observed in control group (Fig. 2e), whereas inflammation, as evidenced by hyperplasia of connective tissue (thick arrow), folliculus pili and hair papilla (ellipse); by infiltrating PMNs (thin arrow) were present in tissue after injection with W/O emulsion (Fig. 2h). The pathologic changes in

Table 2 Heat Stability Study of EAS at $4{ }^{\circ} \mathrm{C}, 25^{\circ} \mathrm{C}$ and $37^{\circ} \mathrm{C}$ (values are shown as means $\pm S D, n=3$ )

\begin{tabular}{|c|c|c|c|c|c|c|c|c|c|}
\hline \multirow[t]{2}{*}{ EAS } & & \multicolumn{8}{|c|}{ Time (months) } \\
\hline & & T0 & 1 & 3 & 6 & 9 & 12 & 18 & 24 \\
\hline \multirow[t]{4}{*}{$4^{\circ} \mathrm{C}$} & Particle size & $104 \pm 2$ & $104 \pm 2$ & $101 \pm 3$ & $105 \pm 1$ & $104 \pm 2$ & $105 \pm 2$ & $107 \pm 2$ & $106 \pm 2$ \\
\hline & Zeta potential & $-38.8 \pm 0.1$ & $-38.3 \pm 0.4$ & $-38.5 \pm 0.2$ & $-38.8 \pm 0.2$ & $-38.7 \pm 0.2$ & $-38.5 \pm 0.2$ & $-38.7 \pm 0.02$ & $-38.3 \pm 0.3$ \\
\hline & $\mathrm{pH}$ & $6.8 \pm 0.1$ & $6.7 \pm 0.2$ & $6.8 \pm 0.1$ & $6.6 \pm 0.3$ & $6.8 \pm 0.1$ & $6.8 \pm 0.1$ & $6.7 \pm 0.3$ & $6.7 \pm 0.2$ \\
\hline & Viscosity & $2.01 \pm 0.14$ & $2.01 \pm 0.21$ & $1.90 \pm 0.17$ & $1.94 \pm 0.17$ & $2.04 \pm 0.15$ & $2.11 \pm 0.01$ & $1.99 \pm 0.04$ & $2.03 \pm 0.12$ \\
\hline \multirow[t]{4}{*}{$25^{\circ} \mathrm{C}$} & Particle size & $104 \pm 2$ & $103 \pm 3$ & $109 \pm 1$ & $114 \pm 2$ & $141 \pm 9$ & ND & ND & ND \\
\hline & Zeta potential & $-38.3 \pm 0.1$ & $-38.4 \pm 0.5$ & $-38.7 \pm 0.3$ & $-38.5 \pm 0.5$ & $-35.4 \pm 0.4$ & ND & ND & ND \\
\hline & $\mathrm{pH}$ & $6.8 \pm 0.2$ & $6.5 \pm 0.3$ & $6.8 \pm 0.1$ & $6.5 \pm 0.3$ & $6.6 \pm 0.2$ & ND & ND & ND \\
\hline & Viscosity & $2.01 \pm 0.05$ & $2.04 \pm 0.01$ & $2.24 \pm 0.23$ & $2.17 \pm 0.05$ & $2.43 \pm 0.22$ & ND & ND & ND \\
\hline \multirow[t]{4}{*}{$37^{\circ} \mathrm{C}$} & Particle size & $105 \pm 2$ & $107 \pm 2$ & $115 \pm 2$ & $157 \pm 12$ & ND & ND & ND & ND \\
\hline & Zeta potential & $-38.6 \pm 0.3$ & $-38.4 \pm 0.2$ & $-36.9 \pm 0.3$ & $-35.8 \pm 0.4$ & ND & ND & ND & ND \\
\hline & $\mathrm{pH}$ & $6.8 \pm 0.2$ & $6.5 \pm 0.3$ & $6.6 \pm 0.2$ & $6.7 \pm 0.2$ & ND & ND & ND & ND \\
\hline & Viscosity & $2.03 \pm 0.11$ & $2.11 \pm 0.18$ & $2.34 \pm 0.19$ & $2.55 \pm 0.38$ & ND & ND & ND & ND \\
\hline
\end{tabular}



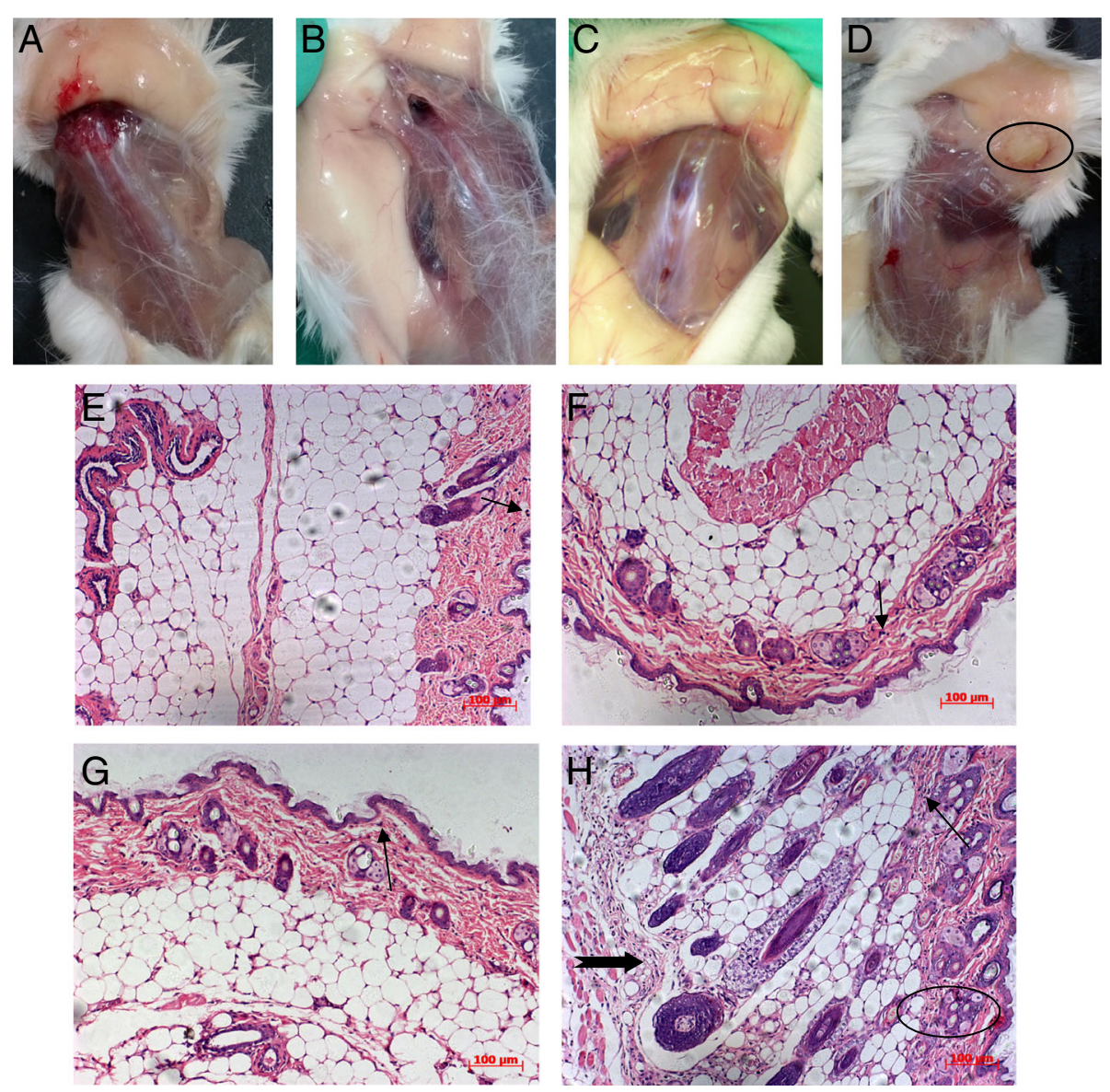

Fig. 2 Toxicity analysis of EAS. a to d: the local reactogenicity of different formulations at the sites of injection. The subcutaneous injection sites of each formulation in female BALB/c mice were observed $72 \mathrm{~h}$ after administration. $\mathbf{a}$ : PBS control; $\mathbf{b}$ : EAS; $\mathbf{c}$ : MF59; $\mathbf{d}$ : W/O formulation. e to $\mathbf{h}$ : the histology of the subcutaneous injection sites of mice (H.E. $\times 100)$. The tissues excised from the sites of administration $72 \mathrm{~h}$ after the injection of each sample were fixed in 10\% formalin and embedded in paraffin for histologic examination. Hematoxylin and eosin stained slides were prepared using standard methods. e: PBS control; f: EAS; $\mathbf{g : ~ M F 5 9 ; ~} \mathbf{h}$ : W/O formulation

the EAS and MF59 emulsion groups were mild and there were no significant differences between these two groups (Fig. $2 \mathrm{f}$ and g).

\section{EAS-adjuvanted vaccine induces a high serum $\mathrm{HI}$ antibody response}

Mice were immunized with swine influenza antigen incorporated into different adjuvants. Sera samples were collected 3 weeks after the first and second immunization. The haemagglutination inhibition (HI) assay was used to evaluate the anti-HA antibody response. As shown in Fig. 3a, all adjuvant formulations induced significantly higher HI titers than the non-adjuvanted vaccine group at days 21 and 42 post-vaccination $(\mathrm{dpv})(P<0.05))$. EAS induced significantly higher $\mathrm{HI}$ titers than the W/O formulation at $42 \mathrm{dpv}(P<0.05))$, although there were no statistically significant difference between them at $21 \mathrm{dpv}(P>0.05)$. Minimal differences in antibody responses were observed between animals immunized with EAS and MF59 adjuvant at 21 and $42 \mathrm{dpv}(P>0.05)$.

\section{EAS-adjuvanted vaccine induces high titers of humoral immune reactive antibody}

Humoral immune responses induced by different formulations were detected by measuring $\mathrm{H} 3 \mathrm{~N} 2$ specific IgG antibodies of vaccinated mice using ELISA. All adjuvant formulations elicited significantly higher total IgG titers compared to antigen alone at both 21 and $42 \mathrm{dpv}(P<0.05$, Fig. $3 \mathrm{~b})$. EAS and MF59 vaccinated groups had significantly higher total IgG titers than the $\mathrm{W} / \mathrm{O}$ formulation at 3 weeks after the first and second immunizations $(P<0.05)$. But there were no statistical differences between EAS and MF59 vaccinated groups $(P>0.05)$. Anti-flu IgG1 and IgG2a serum levels were determined to indicate the different qualitative response types induced by various formulations. As shown in Fig. 3c, all adjuvant formulations significantly increased antigen-specific IgG1 antibodies compared to antigen alone both at 21 and $42 \mathrm{dpv}$ 


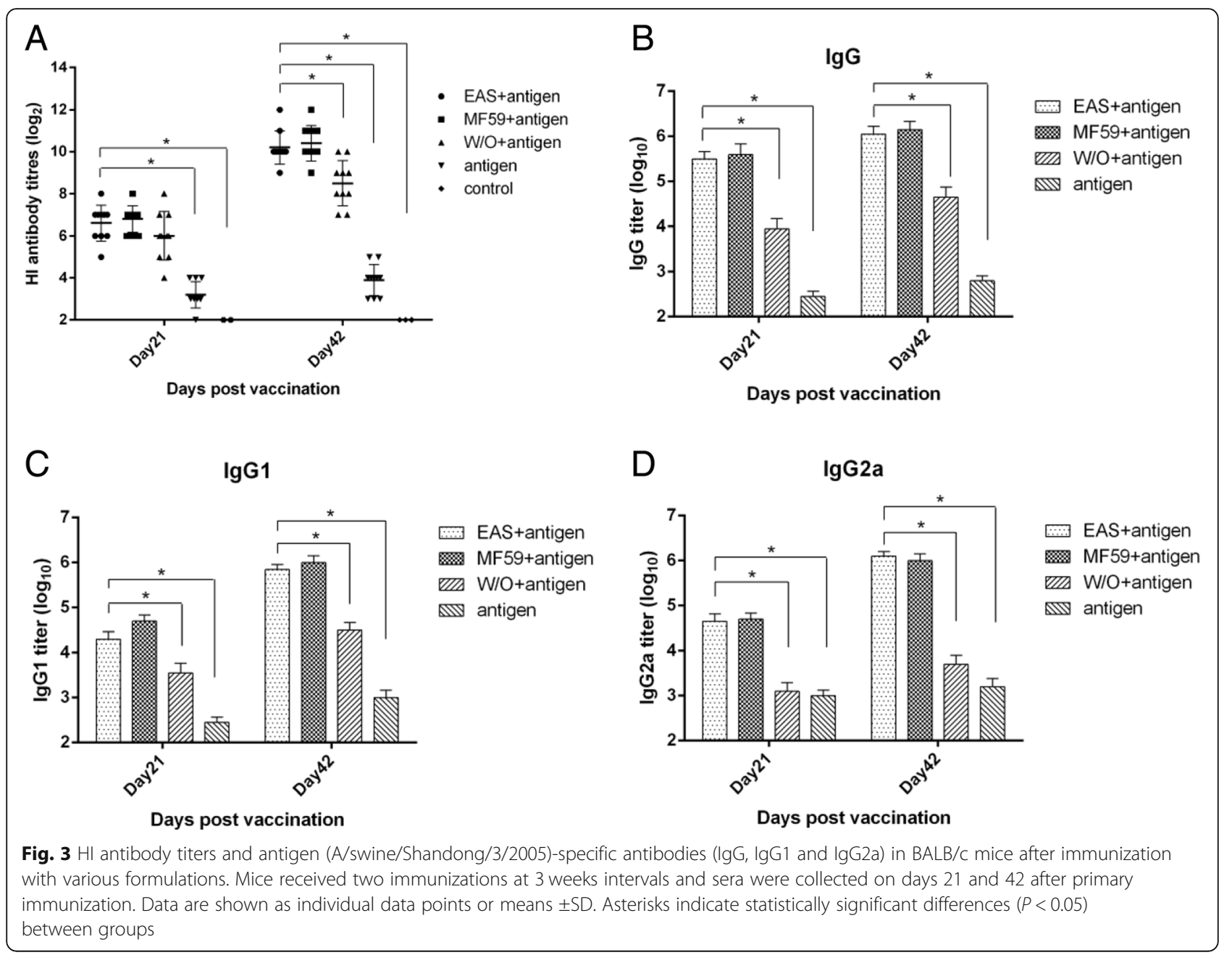

$(P<0.05)$. However, only EAS- or MF59-adjuvanted antigen significantly amplified IgG2a responses compared to the W/O formulation or antigen alone after primary or booster immunization $(P<0.05$, Fig. 3d).

\section{EAS-adjuvanted vaccine elicits high concentrations of cytokines and a mixed Th1/Th2 profile}

The concentration of cytokines in supernatants of ex vivo stimulated splenocytes was measured by radioimmunoassay. No or very low levels of cytokines were detected in the supernatant of splenocytes from control mice. Splenocytes from mice immunized with EAS-adjuvanted vaccine secreted significantly higher levels of Th1 cytokines (IFN- $\gamma$ and IL-2) compared to the $\mathrm{W} / \mathrm{O}$ formulation or antigen alone group 48 h after stimulation $(P<0.05$, Fig. 4). Additionally, higher levels of Th2 cytokines (IL-4 and IL-5) were detected in the EAS-adjuvanted vaccine group compared to the other vaccine groups, although there was no significant difference between them $(P>0.05)$. Cytokine profiles after $48 \mathrm{~h}$ of stimulation were similar between EAS and MF59 vaccine groups.

\section{EAS-adjuvanted vaccine confers effective protection against homologous virus challenge}

All mice survived and no obvious clinical signs were observed after challenge. Virus was not detected in the lungs of immunized mice at $5 \mathrm{dpi}$ except the antigen alone vaccinated group or mock vaccinated group (Table 3). The immunized mice in EAS, MF59 and W/O group showed slight and transient body weight loss $(1 \% \sim 2 \%)$ on $2 \mathrm{dpi}$, and then recovered quickly from $4 \mathrm{dpi}$. In antigen alone immunized group, mice showed mild weight loss (less than $5 \%)$, then they recovered gradually and regained their body weight on 8 dpi. In contrast, mock vaccinated mice displayed significant and progressive weight loss, which lasted 2 weeks, and the worst weight loss with $10.5 \%$ decline occurred on 6 dpi (Fig. 5).

\section{Discussion}

For farm and laboratory animals, the most commonly used emulsion adjuvants are mineral (paraffin) oil-based Freund's complete or incomplete adjuvant. Although these W/O emulsions have adjuvant effects in veterinary vaccines, they are too 


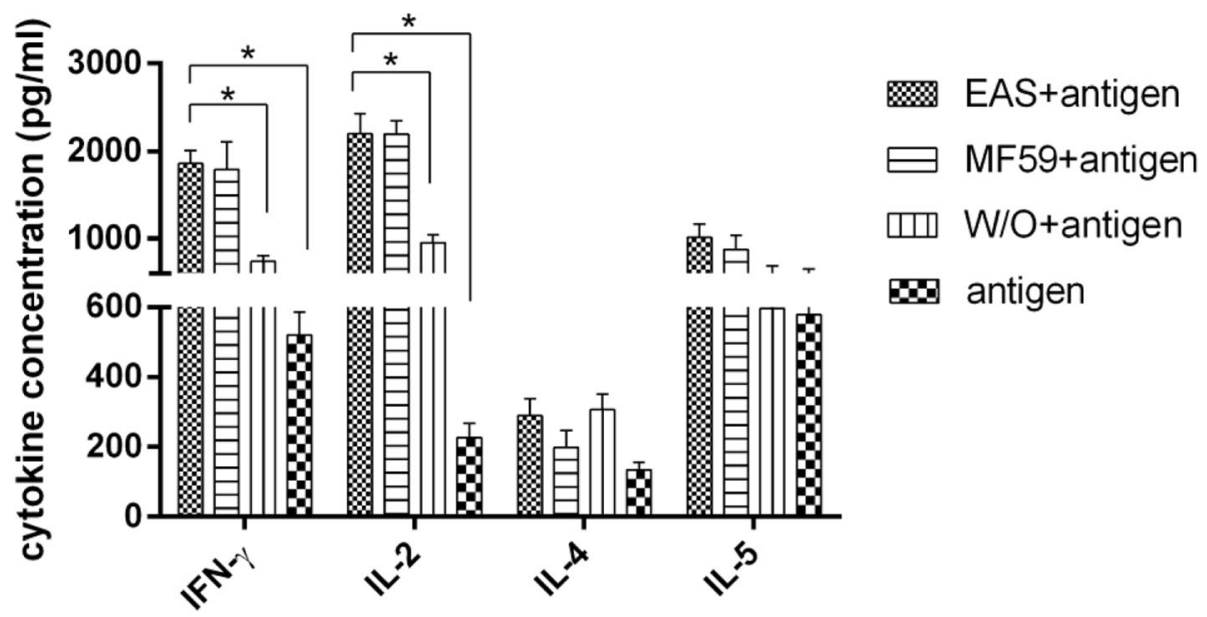

Fig. 4 The cytokine response induced in the spleen of BALB/C mice after immunization with various formulations. Mice $(n=3)$ received 2 immunizations at 3 weeks intervals and splenocytes were collected at day 21 after booster immunization. The cell supernatant was analyzed for influenza-induced IFN- $y, I L-2, I L-4$ and IL-5 by radioimmunoassay after $48 \mathrm{~h}$ of stimulation. Data are shown as means \pm SD. Asterisks indicate statistically significant differences $(P<0.05)$ between groups

reactogenic for routine use [14]. $\mathrm{O} / \mathrm{W}$ emulsion, owing to the generally lower concentration of oils and better safety and tolerability profiles, will likely be preferred for the next generation of adjuvants. The objective of this study was to develop a novel $\mathrm{O} / \mathrm{W}$ emulsion and investigate its adjuvant potential in inactivated swine influenza vaccine. DLS and TEM analyses document that EAS is a homogeneous nanoemulsion with small particle size $(\sim 105 \mathrm{~nm})$ and a low polydispersity index $(0.159 \pm 0.036)$. The low viscosity $\left(2.04 \pm 0.24 \mathrm{cP}\right.$ at $\left.20^{\circ} \mathrm{C}\right)$ was expected because of the small average diameter of the droplets. The small average diameter and low viscosity of EAS will be of benefit following sterile filtration and parenteral administration.

The adjuvant potential of EAS was investigated and compared with the W/O formulation and MF59 adjuvant in mice immunized with inactivated swine influenza virus. The results showed that mice immunized subcutaneously twice with EAS-adjuvanted vaccine had significantly higher titers of $\mathrm{HI}$ and IgG antibodies than the $\mathrm{W} / \mathrm{O}$ formulation or antigen alone $(P<0.05)$, but there was no difference between the EAS-adjuvanted group and MF59adjuvanted group $(P>0.05)$. Remarkably, data from many previous studies indicates that the size of adjuvant particles has an important effect on adjuvant activity and the type of evolving immune responses. For example, Li et al. showed that smaller OVA-conjugated nanoparticles $(\sim 230 \mathrm{~nm})$ induced stronger OVA-specific antibody and cellular immune responses than the larger OVA-nanoparticles $(\sim 780 \mathrm{~nm})$ when subcutaneously injected into mice [15]. Foged et al. [16] and Kanchan et al. [17] also showed that smaller particles $(<500$ $\mathrm{nm}$ ) were more efficiently internalized by DCs and macrophages than larger particles $(>1 \mu \mathrm{m})$. Moreover, the particle size of MF59 $(\sim 160 \mathrm{~nm})$ was optimized in the preparation process by microfluidizer and was crucial to its maximal adjuvant effect for a wide range of antigens in many clinical and pre-clinical studies [18]. Since the mean particle size of EAS was less than $200 \mathrm{~nm}$, we presume that it may have similar effect on its adjuvant efficacy. The correlation between the particle size of EAS and its adjuvant activity will be defined in further studies.

Immunity to influenza is dependent on both antibody and cell mediated immune responses, and both are critical to inducing protective immunity [19-22]. Oil in water adjuvants including MF59 and AS03 were shown to significantly

Table 3 Lung virus isolation from mice of different groups challenge with the homologous virus

\begin{tabular}{ll}
\hline Group & Number of mice carrying H3N2 virus in lung post challenge/total number (Positive rate) \\
\hline EAS + antigen & $0 / 5$ \\
MF59 + antigen & $0 / 5$ \\
W/O + antigen & $0 / 5$ \\
antigen & $1 / 5$ \\
mock & $4 / 5$ \\
\hline
\end{tabular}

Mice were challenged intranasally with $0.2 \times 10^{5}$ EID50 of the H3N2 subtype virus strain A/swine/Shandong/3/2005 two weeks after the second immunization. Five mice of each group were euthanized at 5 days post infection (dpi), and whole lungs were collected and homogenized in PBS. The homogenates were centrifuged and the supernatant from each sample was collected for passage in 10-day-old specific pathogen free (SPF) embryonated chicken eggs. The allantoic fluid was harvested and tested for hemagglutinin activity 


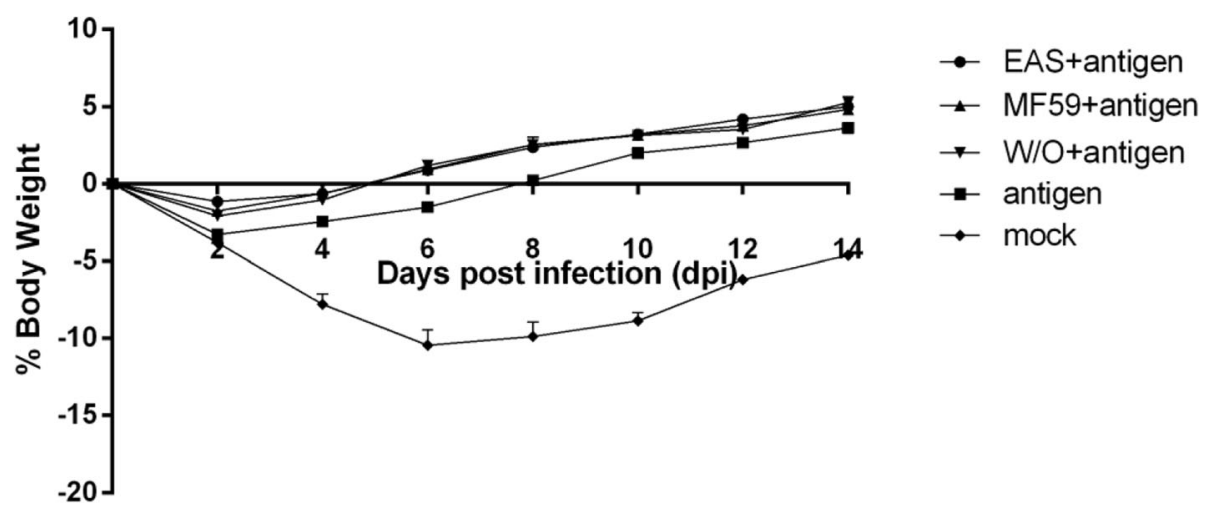

Fig. 5 Weight changes of mice after homologous virus challenge. Mice were challenged intranasally with $0.2 \times 10^{5}$ EID 50 of the H3N2 subtype virus strain A/swine/Shandong/3/2005 two weeks after the second immunization. The survival rate, clinical signs and bodyweight of the challenged mice were monitored for 14 days after the challenge. Data are shown as means \pm SD. Asterisks indicate statistically significant differences $(P<0.05)$ between groups

improve humoral and $\mathrm{T}$ cell responses against human or avian influenza [8-11]. In the current study, although all vaccinated mice induced amplified H3N2 specific ELISA antibodies, only the EAS and MF59 vaccinated groups induced both strong IgG1 and IgG2a antibodies, while the W/O formulation or antigen alone induced predominantly IgG1 antibodies. The predominance of IgG2a isotypes indicates skewing towards Th1 responses, which promotes efficient generation of cytotoxic $\mathrm{T}$ cells resulting in faster virus clearance and recovery after viral infection [23-25]. These results demonstrate that EAS induces a balanced IgG1/IgG2a response and a mixed Th1/Th2 response, which is important for protective immunity against influenza. Furthermore, the cytokine profile from the supernatants of ex vivo stimulated cells showed that the EAS-adjuvanted vaccine induced significantly higher levels of Th1 cytokines compared to the W/O formulation or antigen alone, implying an effective stimulation of the innate immune system and consequent facilitation of enhanced immunity to influenza, as did MF59. Moreover, no virus was detected in the lungs of immunized mice at day 5 post infection except the antigen alone vaccinated group or mock vaccinated group, showing that EAS-adjuvanted vaccine, as well as MF59-adjuvanted vaccine and the conventional $\mathrm{W} / \mathrm{O}$ vaccine could provide effective protection against homologous challenge. Taken together, EAS-adjuvanted vaccine enhanced HI titers, induced virus-specific cell-mediated immune response and provided potent protection against virus challenge. EAS could be a promising candidate adjuvant for veterinary vaccine. Remarkably, although the adjuvant effect of MF59 was due to the fully formulated emulsion [18, 26, 27], we presume that some component of EAS might induce a comparable adjuvant effect. Specifically, carbopol-based adjuvant suspensions have been evaluated in veterinary vaccines against several pathogens [28, 29], and the non-ionic block polymer pluronic ${ }^{\circledR}$ L121 (similar to pluronic ${ }^{\oplus}$ L31 in chemical structure) has been reported to contribute to the potent adjuvant efficacy of the Syntex adjuvant formulation (SAF) [30, 31]. We presume that these ingredients may account for the enhanced immune response of the EAS formulation. Research on the mechanism of action of EAS is ongoing.

For an emulsion to be used for parenteral administration, stability is one of the most important parameters. Many factors are associated with the stability of emulsions, such as initial particle size, uniformity, surface tension and interface charge [32-34]. Emulsions with smaller initial particle size are more stable than those with larger particles [35]. For instance, the small droplet size of MF59 emulsion enhances emulsion stability for at least 2 years at $2-8{ }^{\circ} \mathrm{C}[26,36]$. Moreover, higher zeta potential is closely related to a higher surface charge of colloidal particles and thus has more charge repulsion, which is another indication of the stability of colloidal systems $[35,37]$. The zeta potential of EAS was about $38 \mathrm{mV}$, significantly higher than the common value of 20 to $-30 \mathrm{mV}$ reported for other $\mathrm{O} / \mathrm{W}$ emulsions [37]. This might be due to the use of soy lecithin and carbopol 971P, which contains various anionic fractions. These negatively charged components usually account for a major proportion of surface charge and hence are of great importance to the stability of emulsions. In the current study, EAS was stable for 24 months and did not present any significant physical alteration or phrase separation over the storage period at $4{ }^{\circ} \mathrm{C}$. We presume that the small particle size, low polydispersity index and high zeta potential may contribute to its excellent stability.

Beside the potent adjuvant efficacy and superior stability of EAS, safety is another major concern when considering new adjuvant formulations for vaccine applications. The local reactogenicity and tolerability of EAS was assessed in mice by visual inspection and histological analysis. Although mild 
inflammatory reactions were present in mice injected with EAS, there were no obvious health problems or gross lesions. However, mice injected with the W/O formulation, had adverse reactions at injection sites. The safety profile of EAS should be further tested in pigs or other farm animals in the near future. Moreover, during pandemic, it is very often that antigen is in short and it is important to have an adjuvant to save lots of antigens. Thus, dose-dependent tests are needed. And, it will be also nice to examine whether this adjuvant enhances long-term protection, cross-protection of vaccine and whether the adjuvant will enhance the immunity itself, and so on. These will be investigated in the further study.

\section{Conclusion}

Developing new adjuvant formulations with improved potency, enhanced safety and low viscosity will be of great value for swine industry. The O/W emulsion EAS developed in the present work induced potent humoral and cellular immune responses against inactivated swine influenza virus, conferred effective protection after homologous virus challenge and showed low toxicity in mice, indicating that EAS is as good as the commercial adjuvant MF59. The superiority of EAS to the conventional W/O formulation in adjuvant activity, safety and stability will make it a potential veterinary adjuvant.

\section{Methods}

\section{Adjuvant components and virus}

Squalane (vegetable-based) was purchased from Croda Ltd., Shanghai, China. Polyoxyethylene 20 sorbitan monooleate (polysorbate 80) and Poloxamer 407 were purchased from Sigma-Aldrich (St. Louis, MO, USA). Poly (ethylene glycol) -block-poly (propylene glycol) -block-poly (ethylene glycol) (PEG-PPG-PEG Pluronic ${ }^{\circ}$ L-31) was obtained from BASF Corporation, USA. Soy lecithin (PC 70\%) was purchased from Shanghai Tywei Pharmaceutical Co., Ltd. (Shanghai, China). Polyethylene glycol 400 monooleate (PEG400MO) was purchased from Xinchang pharmaceutical Co., Ltd. (Zhejiang, China). Carbomer 971P was obtained from Lubrizol (Wickliffee, OH, USA). A/swine/Shandong/3/2005 (H3N2 subtype) was isolated from pigs with respiratory disease on farms in eastern China [38]. Viruses were propagated in the allantoic cavities of 10-day-old embryonated specific-pathogen-free (SPF) chicken eggs or in Madin-Darby canine kidney cells (MDCK). The infective allantoic fluid was aliquoted and stored at $-80^{\circ} \mathrm{C}$.

\section{Preparation of emulsion}

The recipe of the emulsion adjuvant was as described in the Chinese patent license with registration number 201310021011.3. Briefly, the lipophilic emulsifiers, PEG-PPG-PEG Pluronic L-31 and soy lecithin were fully dissolved in the oil phase (squalane) and the hydrophilic emulsifiers, polysorbate 80 , Poloxamer 407, and PEG400MO were fully dissolved in the water phase (PBS, pH7.4) containing carbopol 971P. The oil phase was added to the aqueous phase with a high-shear mixer (MICCRA D-9, Nordrhein-Westfalen, Germany) at $11,000 \mathrm{rpm}$ for $15 \mathrm{~min}$ to yield a coarse emulsion. The coarse emulsion was immediately processed through a High Pressure Homogenizer (ATS engineering, Shanghai, China) for six cycles at 1000 bar. Finally, the emulsion was filter-sterilized by $0.22 \mu \mathrm{m}$ filtration (Millipore AS, Oslo, Norway) and adjusted to pH 6.8. Emulsion adjuvant containing squalane was named EAS.

\section{Characterization of emulsion}

Emulsion particle sizing was determined via dynamic light scattering (DLS) with a Mastersizer 2000 (Malvern Instruments, Worcestershire, UK). The size and homogeneity of oil droplets in EAS were observed by transmission electron microscopy (TEM) with a JEM-1230 (JEOL Ltd., Tokyo, Japan), as described previously [39]. Zeta potential was determined on a Zetasizer Nano-ZS 90 (Malvern Instruments Corp., UK). The dynamic viscosity of EAS was measured at $25^{\circ} \mathrm{C}$ using a digital viscometer (DV-II + Pro, Brookfield Engineering Laboratory, Middleboro, MA, USA).

For stability analysis, filter sterilized EAS samples were stored at 4, 25 and $37^{\circ} \mathrm{C}$ over 24 months. Colloidal stability of emulsion was assessed by visual inspection and particle sizing change. Laser light diffraction techniques were used for size measurements because of their wide range of particle sizing, enabling the detection of larger droplets that may appear as a result of emulsion destabilization.

\section{Preparation of vaccine}

The H3N2 subtype swine influenza vaccine was prepared as an $\mathrm{O} / \mathrm{W}$ form. In brief, the H3N2 subtype virus strain $\mathrm{A} /$ swine/Shandong/3/2005 was propagated in allantoic cavities of 10-day-old specific pathogen free (SPF) embryonated chicken eggs. The viral-laden allantoic fluids (1024 HA units per $0.1 \mathrm{ml}$ ) were purified by centrifugation $\left(28,000 \times \mathrm{g}, 30 \mathrm{~min}, 4^{\circ} \mathrm{C}\right)$ and inactivated with $0.5 \%(\mathrm{v} / \mathrm{v})$ $\beta$-propiolactone at $37^{\circ} \mathrm{C}$ for $24 \mathrm{~h}$. Equal volumes of purified virus and EAS were thoroughly mixed on a shaker to manufacture an O/W emulsion vaccine. MF59 emulsion adjuvant and MF59-adjuvanted vaccine was also prepared according to the protocol published for MF59 [26]. Briefly, MF59, consisting of 5\% squalene (v/v), 0.5\% Tween80 (v/ v), $0.5 \%$ Span 85 (v/v) (Sigma, St. Louis, MO, USA) in 20 $\mathrm{mM}$ citrate buffer, was prepared by homogenization at 12,000 psi with a Microfluidizer (model 110Y; Microfluidics, Newton, MA). The emulsion was sterilized by $0.22 \mu \mathrm{m}$ filtration. MF59-adjuvanted vaccine was prepared by thoroughly mixing of purified virus and MF59 at a ratio of $1: 1(\mathrm{v} / \mathrm{v})$. Conventional vaccine in a water-in-oil form (W/ $\mathrm{O}$ vaccine) was prepared as previously described and used as a control [40]. For W/O emulsion vaccine, the purified virus was emulsified in Marcol 52 mineral oil (ESSO, Paris, France) at a ratio of 1:3 (v/v, virus to adjuvant). 


\section{Toxicity analysis}

Female BALB/c mice (18-22 g) purchased from Beijing Merial Vital Laboratory Animal Technology Co., Ltd. (Beijing, China) were housed under specific pathogen-free conditions. Mice from each group $(n=3)$ were inoculated subcutaneously with $200 \mu \mathrm{l}$ of EAS, MF59 or W/O emulsion. Mice in the control group received the same amount of PBS. The tissues excised from the sites of administration $72 \mathrm{~h}$ after injection were fixed in $10 \%$ formalin and embedded in paraffin for histologic examination. Hematoxylin and eosin stained slides were prepared using standard methods [41].

\section{Immunization of mice}

Female BALB/c mice (18-22 g) purchased from Beijing Merial Vital Laboratory Animal Technology Co., Ltd. (Beijing, China) were housed under specific pathogen-free conditions. Mice from each group $(n=20)$ were injected subcutaneously twice with $200 \mu \mathrm{l}$ of $\mathrm{O} / \mathrm{W}$ emulsion vaccines (containing 1024 HA units) or $400 \mu \mathrm{l}$ of W/O vaccine (containing 1024 HA units) at 3 weeks intervals. Mice in the control group received immunizations with $200 \mu \mathrm{l}$ of PBS. Sera were collected 3 weeks after the first and second immunization.

\section{Hemagglutination inhibition titer (HI)}

To determine hemagglutination-inhibition (HI) titers, sera were first treated with receptor-destroying enzyme (RDE) (DenkaSeiken, Tokyo, Japan) by incubation overnight at $37^{\circ} \mathrm{C}$ to eliminate hemagglutination non-specific inhibitors in serum samples. Then, sera were heated at $56^{\circ} \mathrm{C}$ for $30 \mathrm{~min}$ to inactivate the receptor-destroying enzyme. Sera were serially (1:2) diluted, mixed with 4HA units of influenza virus, and incubated for $30 \mathrm{~min}$ at room temperature prior to adding $1 \%$ chicken red blood cells. HI titers are defined as the highest serum dilution completely inhibiting hemagglutination.

\section{Elisa}

Influenza virus-specific antibodies (IgG, IgG1 and IgG2a) were quantified using an ELISA assay, as previously described [42] except that plates were coated with inactivated whole H3N2 influenza virus antigen $(2 \mu \mathrm{g} / \mathrm{ml})$. The titers of IgG, IgG1 and IgG2a were calculated using a four-parameter logistic equation (Softmax software, Molecular Devices). The inflection point of the titration curve was taken as titer value.

\section{Ex vivo re-stimulation of splenocytes}

Antigen-specific $\mathrm{T}$ cell responses were measured following restimulation of splenocytes with whole $\beta$-propiolactone-inactivated $\mathrm{H} 3 \mathrm{~N} 2$ influenza virus. Briefly, splenocytes were isolated from immunized mice and cultured in RPMI-1640 supplemented with $10 \%$ fetal bovine serum, $100 \mathrm{U} / \mathrm{ml}$ penicillin, and $0.1 \mathrm{mg} / \mathrm{ml}$ streptomycin. Splenocytes $\left(2 \times 10^{6}\right.$ cells/well $)$ were then stimulated with inactivated H3N2 influenza virus $(2 \mu \mathrm{g} /$ $\mathrm{ml})$. Forty-eight hours later, cytokines (IL-2, IL-4, IL-5, IFN- $\gamma$ ) were measured from supernatants by radioimmunoassay. Commercial kits were purchased from the Institute of Radiation of Science and Technology Development Center of the General Hospital of People's Liberation Army (Beijing, China). The assay was conducted according to the manufacturer's protocol. All samples were assayed in triplicate.

\section{Virus challenge of immunized mice}

Mice were challenged intranasally with $0.2 \times 10^{5}$ EID50 of the H3N2 subtype virus strain $\mathrm{A} /$ swine/Shandong/3/2005 two weeks after the second immunization. Five mice of each group were euthanized at day 5 post infection (dpi), and whole lungs were collected and homogenized in PBS. The homogenates were centrifuged and the supernatant from each sample was collected for passage in 10-day-old specific pathogen free (SPF) embryonated chicken eggs. The allantoic fluid was harvested and tested for hemagglutinin activity. The survival rate, clinical signs and bodyweight of the remaining mice were monitored for 14 days after the challenge.

\section{Statistical analyses}

Data were expressed as individual data points or means \pm standard deviation (SD). Differences were evaluated by one-way analysis of variance (ANOVA) followed by post-hoc tests. Differences were considered significant at a $P$-value $<0.05$.

\section{Ethics statement}

Protocols involving mice were approved by the Institutional Animal Care and Use Committee and were conducted following the guidelines of the Institutional Biosafety Committee at the Jiangsu Academy of Agriculture Sciences. Efforts were made to minimize animal suffering. All the animals were euthanized after the study in a chamber with carbon dioxide (BIOSCAPE, $\mathrm{CO}_{2}$ - box model L). The animals were placed into $\mathrm{CO}_{2}-$ box and $100 \%$ carbon dioxide was imported. The following ratios of $\mathrm{CO}_{2} / \mathrm{O}_{2} \% \mathrm{vol} / \mathrm{min}$ were applied for induction $5 / 95 \% \mathrm{vol} / \mathrm{min}$ and for euthanasia $100 /$ $0 \% \mathrm{vol} / \mathrm{min}$. The secondary physical method of euthanasia was performed by decapitation. In the progress, the animals were unconscious.

\section{Abbreviations \\ DLS: Dynamic light scattering; dpv: Days post-vaccination; EAS: Emulsion Adjuvant containing Squalane; HI: Hemagglutination inhibition titer; MDCK: Madin-Darby canine kidney; O/W: Oil in water; \\ PEG400MO: Polyethylene glycol 400 monooleate; PEG-PPG-PEG: Poly (ethylene glycol) -block-poly (propylene glycol) -block-poly (ethylene glycol); polysorbate 80: Polyoxyethylene 20 sorbitan monooleate; RDE: Receptor- destroying enzyme; SD: Standard deviation; SPF: specific-pathogen-free; TEM: Transmission electron microscopy; W/O: Water in oil}

\section{Acknowledgments}

The authors wish to express their thanks to Dr. Howard Gelberg (Oregon State University) for manuscript editing. 


\section{Funding}

This work was supported by the National Natural Science Foundation of China (No. 31772701, 31672515, 31472164), the Special Fund for Independent Innovation of Agricultural Science and Technology in Jiangsu Province of China (No. cx (17) 3027). The article processing charge was covered by National Natural Science Foundation of China (No. 31772701) and the Special Fund for Independent Innovation of Agricultural Science and Technology in Jiangsu Province of China (No. cx (17) 3027).

\section{Availability of data and materials}

The data analyzed during the current study are available from the corresponding author on reasonable request.

\section{Authors' contributions}

Conceived and designed the experiments: JQZ, JFM, YL and JBH. Performed the animal experiments: JQZ, JFM, XGH, BHD and FL. Analyzed the data: YHZ and CD. Wrote and revised the manuscript: JQZ and JFM. All authors read and approved the final manuscript.

\section{Ethics approval}

All animal tests were approved by the Institutional Animal Care and Use Committee and were conducted following the guidelines of the Institutional Biosafety Committee at the Jiangsu Academy of Agriculture Sciences. The use of $\mathrm{CO}_{2}$ as a method of euthanasia has been approved by the Ethics Committee. This method is within the AVMA Guidelines for the Euthanasia of Animals and guidelines of the China Council on Animal Care.

\section{Consent for publication}

Not applicable.

\section{Competing interests}

The authors declare that they have no competing interests.

\section{Publisher's Note}

Springer Nature remains neutral with regard to jurisdictional claims in published maps and institutional affiliations.

\section{Author details}

${ }^{1}$ National Research Center for Veterinary Vaccine Engineering and Technology of China, Jiangsu Academy of Agricultural Sciences, Nanjing 210014, China. ${ }^{2}$ College of Veterinary Medicine, Nanjing Agricultural University, Nanjing 210095, China. ${ }^{3}$ Shanghai Veterinary Research Institute, Chinese Academy of Agricultural Sciences, Shanghai 200241, China.

\section{Received: 13 February 2018 Accepted: 27 November 2018} Published online: 22 December 2018

\section{References}

1. Brockmeier S L, Register K B, Nicholson T L, et al. Bordetellosis Diseases of swine. 10th ed. Wiley-Blackwell. 2012:670-79.

2. Crisci E, Mussá T, Fraile L, Montoya M. Review: influenza virus in pigs. Mol Immunol. 2013;55:200-11.

3. Pearce MB, Jayaraman A, Pappas C, Belser JA, Zeng H, Gustin KM, Maines TR, Sun X, Raman R, Cox NJ, Sasisekharan R, Katz JM, Tumpey TM. Pathogenesis and transmission of swine origin a $(\mathrm{H} 3 \mathrm{~N} 2) \vee$ influenza viruses in ferrets. Proc Natl Acad Sci U S A. 2012;109:3944-9.

4. Yassine HM, Al-Natour MQ, Lee CW, Saif YM. Interspecies and intraspecies transmission of triple reassortant H3N2 influenza a viruses. Virol J. 2007;4: 129. https://doi.org/10.1186/1743-422X-4-129.

5. Van Reeth K, Ma W. Swine influenza virus vaccines: to change or not to change-that's the question. Curr Top Microbiol Immunol. 2013;370:173-200.

6. Aucouturier J, Dupuis L, Ganne V. Adjuvants designed for veterinary and human vaccines. Vaccine. 2001;19:2666-72.

7. Petrovsky N, Aguilar JC. Vaccine adjuvants: Current state and future trends. Immunol Cell Biol. 2004;82:488-96.

8. Dell'Era L, Corona F, Daleno C, Scala A, Principi N, Esposito S. Immunogenicity, safety and tolerability of MF59-adjuvanted seasonal influenza vaccine in children with juvenile idiopathic arthritis. Vaccine. 2012;30:936-40.

9. Stephenson I, Bugarini R, Nicholson KG, Podda A, Wood JM, Zambon MC, Katz JM. Cross-reactivity to highly pathogenic avian influenza H5N1 viruses after vaccination with nonadjuvanted and MF59-adjuvanted influenza a/
duck/Singapore/97 (H5N3) vaccine: a potential priming strategy. J Infect Dis. 2005;191:1210-5.

10. Morel S, Didierlaurent A, Bourguignon P, Delhaye S, Baras B, Jacob V. Adjuvant system AS03 containing a-tocopherol modulates innate immune response and leads to improved adaptive immunity. Vaccine. 2011;29:2461-73.

11. Vesikari T, Richardus JH, Berglund J, Korhonen T, Flodmark CE, Lindstrand A Silfverdal SA, Bambure V, Caplanusi A, Dieussaert I, Roy-Ghanta S, Vaughn DW. Immunogenicity and safety of a trivalent inactivated influenza vaccine in children 6 months to 17 years of age, previously vaccinated with an AS03-adjuvanted a (H1N1) Pdm09 vaccine: two open-label, randomized trials. Pediatr Infect Dis J. 2015;34:774-82.

12. Orr MT, Fox CB, Baldwin SL, Sivananthan SJ, Lucas E, Lin S, Phan T, Moon JJ, Vedvick TS, Reed SG, Coler RN. Adjuvant formulation structure and composition are critical for the development of an effective vaccine against tuberculosis. J Control Release. 2013;172:190-200.

13. Lawrence MJ, Rees GD. Microemulsion-based media as novel drug delivery systems. Adv Drug Deliv Rev. 2000;45:89-121.

14. Stills HF Jr. Adjuvants and antibody production: dispelling the myths associated with freund's complete and other adjuvants. ILAR J. 2005;46:280-93.

15. Li X, Sloat BR, Yanasarn N, Cui Z. Relationship between the size of nanoparticles and their adjuvant activity: data from a study with an improved experimental design. Eur J Pharm Biopharm. 2011;78:107-16.

16. Foged C, Brodin B, Frokjaer S, Sundblad A. Particle size and surface charge affect particle uptake by human dendritic cells in an in vitro model. Int J Pharm. 2005;298:315-22.

17. Kanchan V, Panda AK. Interactions of antigen-loaded polylactide particles with macrophages and their correlation with the immune response. Biomaterials. 2007;28:5344-57.

18. O'Hagan DT, Ott GS, De Gregorio E, Seubert A. The mechanism of action of MF59-an innately attractive adjuvant formulation. Vaccine. 2012;30:4341-8.

19. Cox F, Baart M, Huizingh J, Tolboom J, Dekking L, Goudsmit J, Saeland E, Radošević $\mathrm{K}$. Protection against H5N1 influenza virus induced by matrix-M adjuvanted seasonal virosomal vaccine in mice requires both antibodies and T cells. PLoS One. 2015; 10(12):e0145243. https://doi.org/10.1371/journal.pone.0145243.

20. Kulkarni RR, Rasheed MA, Bhaumik SK, Ranjan P, Cao W, Davis C, Marisetti K, Thomas S, Gangappa S, Sambhara S, Murali-Krishna K. Activation of the RIG-I pathway during influenza vaccination enhances the germinal center reaction, promotes $\mathrm{T}$ follicular helper cell induction, and provides a dosesparing effect and protective immunity. J Virol. 2014;88:13990-4001.

21. Chua BY, Wong CY, Mifsud EJ, Edenborough KM, Sekiya T, Tan AC, Mercuri F, Rockman S, Chen W, Turner SJ, Doherty PC, Kelso A, Brown LE, Jackson DC. Inactivated influenza vaccine that provides rapid, innate-immune-system-mediated protection and subsequent long-term adaptive immunity. MBio. 2015;6(6):e01024-15.

22. Cox RJ, Brokstad KA, Ogra P. Influenza virus: immunity and vaccination strategies. Comparison of the immune response to inactivated and live, attenuated influenza vaccines. Scand J Immunol. 2004;59:1-15.

23. Thomas PG, Keating R, Hulse-Post DJ, Doherty PC. Cell-mediated protection in influenza infection. Emerg Infect Dis. 2006;12:48-54.

24. Hovden AO, Cox RJ, Haaheim LR. Whole influenza virus vaccine is more immunogenic than split influenza virus vaccine and induces primarily an IgG2a response in BALB/c mice. Scand J Immunol. 2005;62(1):36-44.

25. Moran TM, Park H, Fernandez-Sesma A, Schulman JL. Th2 responses to inactivated influenza virus can be converted to Th1 responses and facilitate recovery from heterosubtypic virus infection. J Infect Dis. 1999;180(3):579-85

26. Ott G, Barchfeld GL, Chernoff D, Radhakrishnan R, van Hoogevest $P$, Van Nest G. MF59. Design and evaluation of a safe and potent adjuvant for human vaccines. Pharm Biotechnol. 1995;6:277-96.

27. Calabro S, Tritto E, Pezzotti A, Taccone M, Muzzi A, Bertholet S, De Gregorio E, O'Hagan DT, Baudner B, Seubert A. The adjuvant effect of MF59 is due to the oil-in-water emulsion formulation, none of the individual components induce a comparable adjuvant effect. Vaccine. 2013;31:3363-9.

28. Mair KH, Koinig H, Gerner W, Höhne A, Bretthauer J, Kroll JJ, Roof MB, Saalmüller A, Stadler K, Libanova R. Carbopol improves the early cellular immune responses induced by the modified-life vaccine Ingelvac PRRS ${ }^{\oplus}$ MLV. Vet Microbiol. 2015;176:352-7.

29. Holmes MA, Townsend HG, Kohler AK, Hussey S, Breathnach C, Barnett C, Holland R, Lunn DP. Immune responses to commercial equine vaccines against equine herpesvirus-1, equine influenza virus, eastern equine encephalomyelitis, and tetanus. Vet Immunol Immunopathol. 2006;111:67-80. 
30. Hjorth RN, Bonde GM, Piner ED, Goldberg KM, Levner MH. The effect of Syntex adjuvant formulation (SAF-m) on humoral immunity to the influenza virus in the mouse. Vaccine. 1997;15:541-6.

31. Hunter RL Overview of vaccine adjuvants: present and future. Vaccine. 2002;20:57-12.

32. Silva AL, Marcelino HR, Verissimo LM, Araujo IB, Agnez-Lima LF, do Egito ES. Stearylamine-containing cationic nanoemulsion as a promising carrier for gene delivery. J Nanosci Nanotechnol. 2016;16:1339-45.

33. Kulkarni CV, Moinuddin Z, Agarwal Y. Effect of fullerene on the dispersibility of nanostructured lipid particles and encapsulation in sterically stabilized emulsions. J Colloid Interface Sci. 2016;480:69-75.

34. Kim YH, Koczo K, Wasan DT. Dynamic film and interfacial tensions in emulsion and foam systems. J Colloid Interface Sci. 1997;187:29-44.

35. Yue H, Ma G. Polymeric micro/nanoparticles: particle design and potential vaccine delivery applications. Vaccine. 2015;33:5927-36.

36. O'Hagan DT, Ott GS, Nest GV, Rappuoli R, Giudice GD. The history of MF59( $\left.{ }^{(}\right)$ adjuvant: a phoenix that arose from the ashes. Expert Rev Vaccines. 2013;12:13-30.

37. Fox CB, Baldwin SL, Duthie MS, Reed SG, Vedvick TS. Immunomodulatory and physical effects of oil composition in vaccine adjuvant emulsions. Vaccine. 2011;29:9563-72.

38. Qi X, Jiao Y, Pan H, Cui L, Fan W, Huang B, Shi Z, Wang H. Genetic analysis and rescue of a triple-reassortant $\mathrm{H} 3 \mathrm{~N} 2$ influenza a virus isolated from swine in eastern China. Virol Sin. 2009:24:52-8.

39. Cai W, Deng W, Yang H, Chen X, Jin F. A propofol microemulsion with low free propofol in the aqueous phase: formulation, physicochemical characterization, stability and pharmacokinetics. Int J Pharm. 2012;436:536-44.

40. Tang Y, Lu J, Wu P, Liu Z, Tian Z, Zha G, Chen H, Wang Q, Wang Q, Hou F, Kang SM, Hou J. Inactivated vaccine with adjuvants consisting of pattern recognition receptor agonists confers protection against avian influenza viruses in chickens. Vet Microbiol. 2014;172:120-8.

41. Miao J, Zhang J, Zheng L, Yu X, Zhu W, Zou S. Taurine attenuates Streptococcus uberis-induced mastitis in rats by increasing $T$ regulatory cells. Amino Acids. 2012;42:2417-28.

42. Mantile F, Trovato M, Santoni A, Barba P, Ottonello S, De Berardinis P, Prisco A. Alum and squalene-oil-in-water emulsion enhance the titer and avidity of anti-A $\beta$ antibodies induced by multimeric protein antigen (1-11) E2, preserving the lgg1-skewed isotype distribution. PLoS One. 2014;9(7): e101474. https://doi.org/10.1371/journal.pone.0101474.

Ready to submit your research? Choose BMC and benefit from:

- fast, convenient online submission

- thorough peer review by experienced researchers in your field

- rapid publication on acceptance

- support for research data, including large and complex data types

- gold Open Access which fosters wider collaboration and increased citations

- maximum visibility for your research: over $100 \mathrm{M}$ website views per year

At $\mathrm{BMC}$, research is always in progress.

Learn more biomedcentral.com/submissions 